\title{
Rancang Bangun Sistem Informasi Rawa BaTIK Berbasis Web
}

\author{
Much Rifani, Jaka Permadi, Winda Aprianti* \\ Program Studi Teknologi Informasi, Politeknik Negeri Tanah Laut Kalimantan Selatan \\ *e-mail : winda@politala.ac.id
}

\begin{abstract}
Abstrak
Sistem pendaftaran Rawa BaTIK (Ruang Kegiatan Warga Belajar Aplikasi dan TIK) yang dikelola oleh Dinas Komunikasi dan Informatika Kabupaten Tanah Bumbu saat ini masih dilakukan dengan cara manual atau langsung ke kantor Dinas Kominikasi dan Informatika. Kantor Dinas Komunikasi dan Informatika yang jaraknya cukup jauh dari Pusat Kota Tanah Bumbu hal ini tentu saja memberatkan bagi Pelajar atau Masyarakat yang ingin mendaftar. Berdasarkan permasalahan tersebut, diperlukan suatu sistem yang dapat memfasilitasi para calon peserta untuk mendaftar secara online agar tidak perlu lagi datang ke kantor Dinas Komunikasi dan Informatika, maka dibuatlah Sistem Informasi Rawa BaTIK (Ruang Masyarakat Belajar Aplikasi dan TIK) Berbasis Web. Pembuatan sistem ini menggunakan metode waterfall dimana pembangunan sistem informasi menggunakan bahasa pemrograman PHP yang kemudian diuji menggunakan black box. Sistem informasi Rawa BaTIK telah berhasil dibangun dan hasil pengujian juga menunjukkan fungsionalitas sistem dapat berfungsi sesuai dengan hasil yang diharapkan.
\end{abstract}

Kata kunci : Black Box, Rawa BaTIK, Sistem Informasi,

Abstract

The registration system of Rawa BaTIK (Room for Citizens Learning Application and ICT) that managed by the Tanah Bumbu District Office of Communication and Information is still being done manually where citizens must come to the Communication and Information Office directly. The distance of the Location of the Office of Communication and Information Office and Tanah Bumbu City Center is burdensome for students or people who want to register. Based on these problems, we need a system that can facilitate prospective participants to register online so that they no longer need to come to the office of the Office of Communication and Information, so that we create The Rawa BaTIK (Room for Citizens Learning Application and ICT) Information System. The making of system uses the waterfall method where the development of information systems uses the PHP programming language which is then tested using a black box. The Rawa BaTIK information system has been successfully built and the test results also show the system's functionality can function in accordance with the expected results.

Keywords : Black Box, Information System, Rawa BaTIK

\section{PENDAHULUAN}

Dinas Komunikasi dan Informatika Kabupaten Tanah Bumbu mempunyai sebuah pusat studi bernama Ruang Aktivitas Warga Belajar Aplikasi dan Teknologi Informasi Komunikasi yang biasa disebut dengan Rawa BaTIK. Rawa BaTIK bertujuan untuk membuka kesempatan agar pelajar atau masyarakat Kabupaten Tanah Bumbu bisa belajar di dalam pusat studi tersebut. Rawa BaTIK dibangun oleh Dinas Komunikasi dan Informatika Kabupaten Tanah Bumbu bekerjasama dengan relawan Teknologi Informasi dan Komunikasi (TIK) Indonesia Cabang Tanah Bumbu. Tim Rawa BaTIK disusun dan dipimpin oleh Sekretaris Dinas Komunikasi dan Informatika Kabupaten Tanah Bumbu.

Sistem pembelajaran Rawa BaTIK menerapkan tiga tahap, yakni teori, praktek, dan pengujian. Bulan pertama peserta diberikan teori tentang pemrograman aplikasi, networking, wordpress, multimedia, public speaking, dan star-up. Bulan kedua peserta dikirim ke desa untuk membantu pembuatan website dan profile desa dengan bermodalkan teori yang diajarkan pada bulan pertama. Setelah satu bulan di desa 
maka para peserta akan mempresentasikan hasil website dan profile desa yang dibuat. Apabila peserta memenuhi semua penilaian, maka peserta akan mendapatkan sertifikat yang ditandatangani langsung oleh Bupati Kabupaten Tanah Bumbu. Apabila peserta tidak memenuhi semua penilaian, maka peserta tetap mendapat sertifikat tetapi hanya ditanda tangani oleh kepala sekolah pusat studi Rawa BaTIK saja.

Saat ini peserta Rawa BaTIK yang mengikuti pusat studi Rawa BaTIK baru berasal dari Pelajar. Sistem pendaftaran dilakukan dengan cara manual, yakni calon peserta langsung datang ke kantor Dinas Komunikasi dan Informatika Kabupaten Tanah Bumbu. Sedangkan untuk pemberitahuan kelulusan sebagai peserta yang berhak mengikuti pusat studi Rawa BaTIK dilakukan dengan cara menghubungi peserta melalui telepon. Sistem pendaftaran dan pengumuman ini kurang efisien dilihat dari segi waktu.Ketidakefisienan ini secara garis besar dikarenakan oleh dua hal. Pertama, kantor Dinas Komunikasi dan Informatika yang jaraknya cukup jauh dari pusat Kota Tanah Bumbu tentu memberatkan bagi pelajar yang ingin mendaftar. Kedua, proses pemberitahuan yang mengharuskan menghubungi satu persatu calon peserta yang mendaftar di pusat studi Rawa BaTIK.

Berdasarkan permasalahan yang diuraikan, diperlukan sebuah sistem yang dapat memudahkan pendaftaran bagi peserta dan memudahkan pemberitahuan kelulusan kepada peserta bagi pengelola Rawa BaTIK. Sistem pendaftaran yang telah dibangun oleh peneliti sebelumnya, yakni oleh Sidik dan Rahmawati (2018), Sarwindah (2018), dan Lestari dan Mirchandini (2018) menyimpulkan bahwa sistem pendaftaran mempermudah pengelolaan sistem pendaftaran. Sistem pendaftaran yang dibangun oleh Lestari dan Mirchandini hanya dapat digunakan oleh panitia,dan Pembina, dimana peserta yang melakukan pendaftaran masih harus datang ke tempat pendaftaran. Sedangkan penelitian oleh Sidik dan Rahmawati, serta Sarwindah telah membangun sistem berbasis web yang dapat digunakan oleh peserta dan panitia. Sistem pendaftaran berbasis web ini mempermudah sistem pendaftaran karena peserta dapat melakukan pendaftaran diman dan kapan saja.

Sistem untuk menjawab permasalahan ini maka perlu dibuat "Sistem Informasi Rawa BaTIK Berbasis Web" yang bertujuan untuk memudahkan para calon peserta untuk mendaftar, melihat kegiatan yang dilakukan, melihat data peserta, melihat data pengajar dan melihat agenda dari Pusat Studi Rawa BaTIK, agar para calon peserta tertarik untuk bergabung dengan Pusat Studi Rawa BaTIK.

\section{METODE PENELITIAN}

Berdasarkan kajian pada Rosa dan Shalahudin (2013) serta penelitian Sidik dan Rahmawati (2018), Sarwindah (2018), dan Lestari dan Mirchandini (2018), metode penelitian yang digunakan adalah metode waterfall. Pembuatan sistem informasi Rawa BaTIK menggunakan metode waterfall yang diuraikan sebagai berikut.

1. System requirement, tahapan ini dilakukan dengan mewawancarai Sekretaris Dinas Komunikasi dan Informatika Kabupaten Tanah Bumbu untuk mengetahui kebutuhan dalam pembangunan sistem informasi Rawa BaTIK.

2. Analysis, tahapan ini dilakukan untuk proses pengumpulan kebutuhan perangkat lunak agar dapat dipahami oleh Dinas Komunikasi dan Informatika Kabupaten Tanah Bumbu dan peserta studi Rawa BaTIK. Kemudian menganalisa data-data yang akan digunakan untuk membangun sistem informasi Rawa BaTIK.

3. Design, tahapan ini dilakukan proses perancangan pada bagian desain sistem Rawa BaTIK yang akan dibangun, meliputi struktur data, arsitektur perangkat, dan antarmuka program.

4. Coding, tahapan ini dilakukan prose pembuatan kode program menggunakan bahasa pemrograman PHP.

5. Testing, tahapan ini dilakukan proses menguji hasil sistem yang telah dibangun dari segi fungsi dan fitur program sehingga dapat diketahui ke siapa program untuk digunakan oleh pengguna. Tahapan testing dilakukan oleh Sekretaris Dinas Komunikasi dan Informatika Kabupaten Tanah Bumbu 
dengan metode blackbox.

\section{HASIL DAN PEMBAHASAN}

\section{Analisa Sistem}

Berdasarkan hasil wawancara dengan Sekretaris Dinas Komunikasi dan Informatika Kabupaten Tanah Bumbu diperoleh analisis sistem berjalan diilustrasikan pada Gambar 1 dan analisis sistem yang diusulkan diilustrasikan pada Gambar 2.

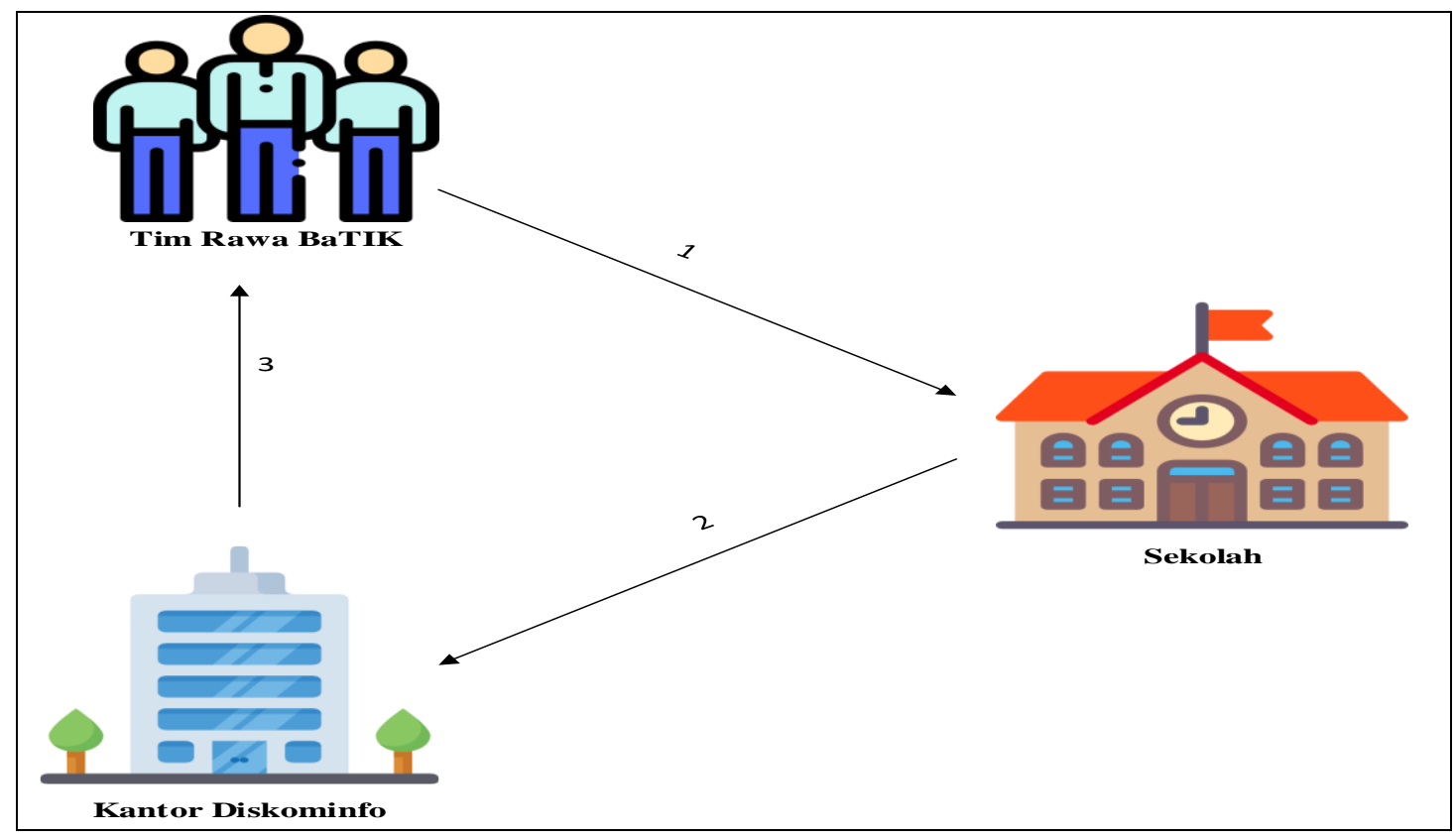

Gambar 1. Sistem yang Berjalan

Penjelasan Gambar 1 diuraikan sebagai berikut.

1. Tim Rawa BaTIK melakukan sosialisasi ke sekolah-sekolah yang telah terdata dan menjelaskan tentang Rawa BaTIK.

2. Guru dari murid yang ingin Rawa BaTIK datang ke kantor Dinas Komunikasi dan Informatika Tanah Bumbu untuk mendaftarkan siswanya yang ingin bergabung ke Rawa BaTIK.

3. Kemudian murid-murid yang mendaftar ke kantor Dinas Komunikasi dan Informatika tadi nantinya akan dicek berkasnya oleh tim dari Rawa BaTIK jika data lengkap maka akan langsung terdaftar. 


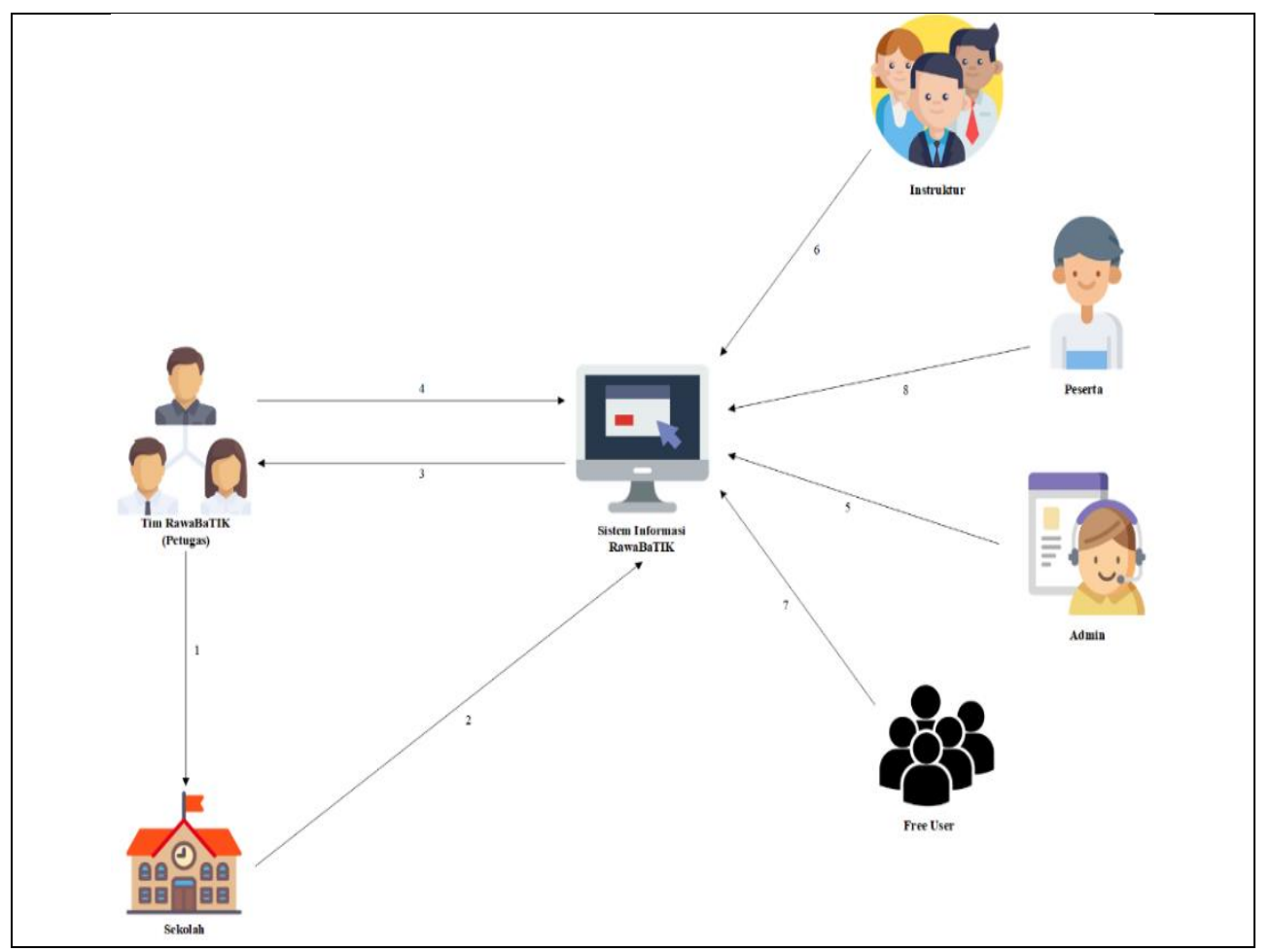

Gambar 2. Sistem yang Diusulkan

Penjelasan Gambar 2 diuraikan sebagai berikut.

1. Tim Rawa BaTIK melakukan sosialisasi ke sekolah-sekolah untuk memperkenalkan Rawa BaTIK dan juga memperkenalkan Sistem Informasi Rawa Batik.

2. Para guru bisa mendaftarkan muridnya atau muridnya bisa langsung mendaftar sendiri kedalam Sistem Informasi yang telah dibangun dan tidak perlu datang langsung ke kantor Dinas Komunikasi dan Informatika untuk mendaftar.

3. Sistem Informasi RawaBaTIK memberikan data dari para pendaftar yang nantinya akan diperiksa oleh petugas RawaBaTIK.

4. Petugas memeriksa data-data dari para pendaftar baru yang nantinya akan diterima atau ditolak untuk masuk ke RawaBaTIK.

5. Admin bertugas untuk membuat akun baru dari petugas, instruktur dan peserta. Admin juga dapat memasukkan data peserta baru dan instruktur baru.

6. Instruktur bertugas untuk memberikan materi-materi baru, memeriksa tugas-tugas yang dikirim dari peserta dan memberikan penilaian kepada setiap peserta.

7. Free User disini dapat melihat-lihat informasi dari sistem informasi Rawa BaTIK ini dan juga dapat melakukan pendaftaran.

8. Peserta yang berasal dari free user yang telah mendaftar atau dari sekolah yang telah mendaftar bisa menerima materi, mengirim tugas dan mendapat penilaian dari para instruktur.

\section{Pembuatan Sistem Informasi Rawa BaTIK}

Berdasarkan analisa sistem yang telah diuraikan, maka dibangun struktur database yang dapat dilihat pada Gambar 3. 


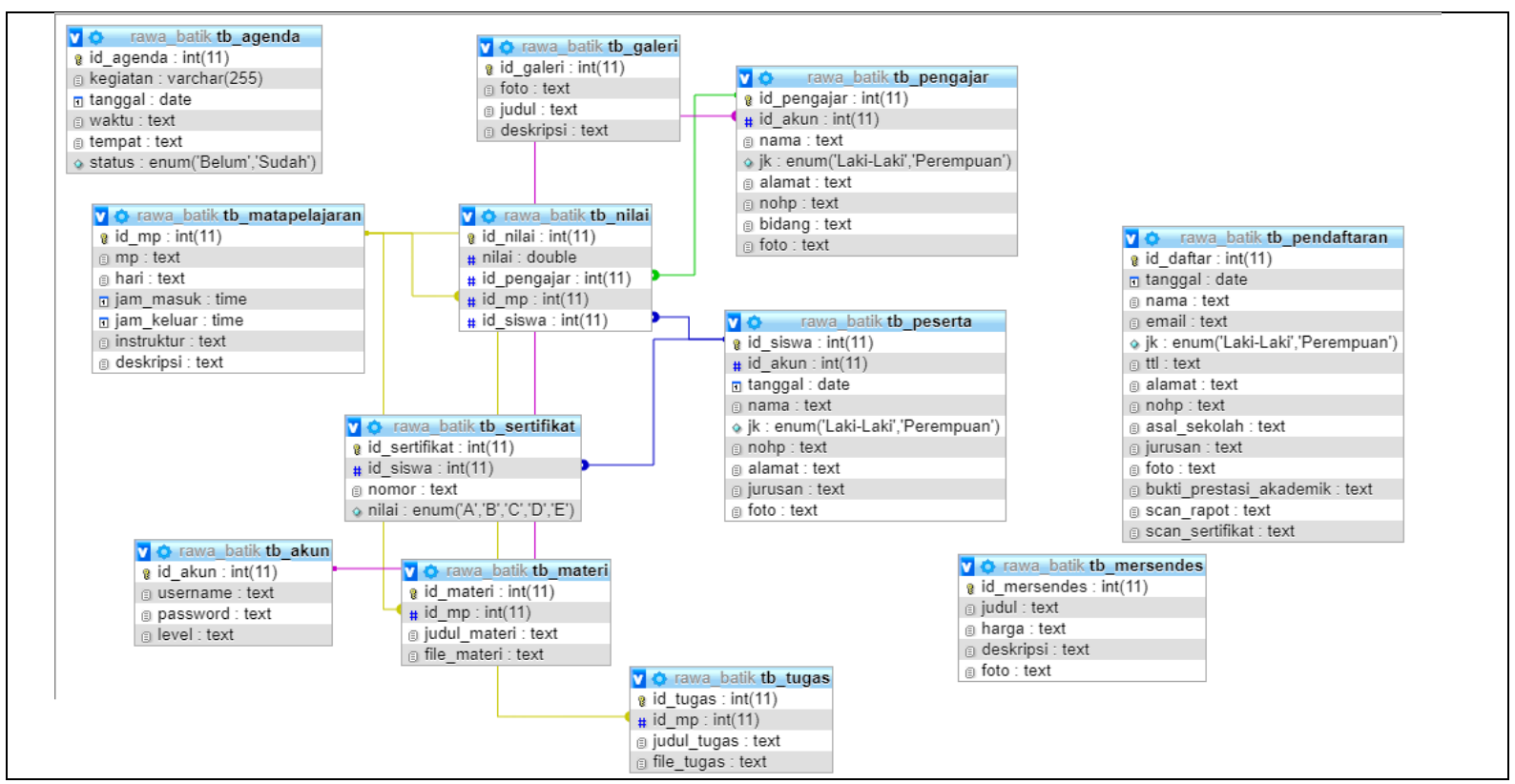

Gambar 3. Struktur Database

Diagram konteks Sistem Informasi Rawa BaTIK dapat dilihat pada Gambar 4.

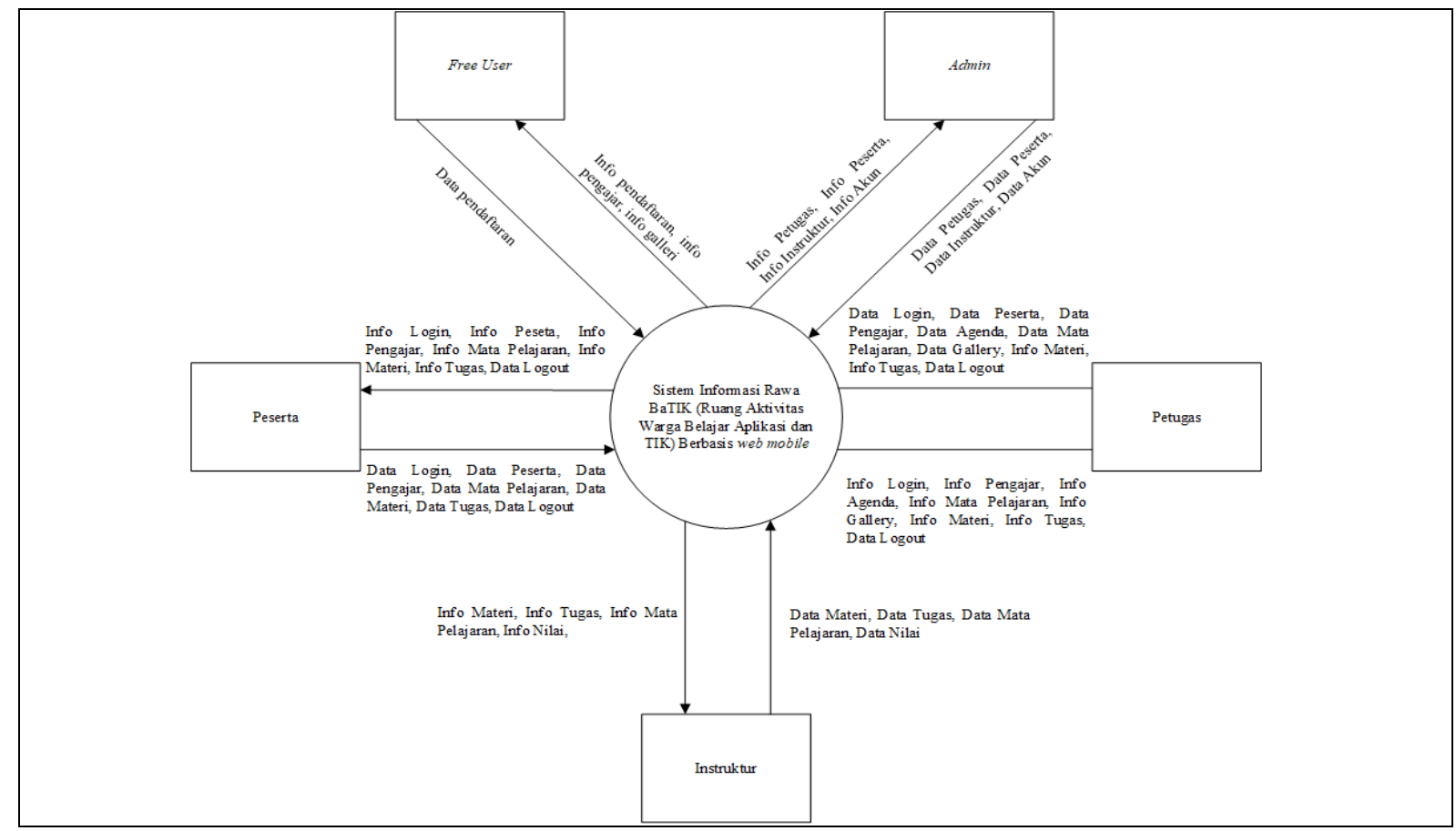

Gambar 4. Diagram Konteks

Gambar 4 menunjukkan bahwa Sistem Informasi Rawa BaTIK dapat digunakan oleh 5 (lima) pengguna, yakni peserta, instruktur, petugas, admin, dan free user. Admin dapat mengelola data petugas, data peserta, data instruktur, dan data akun. Petugas dapat mengelola data peserta, data pengajar, data agenda, data mata pelajaran, data galeri, info materi, dan info tugas. Instruktur dapat mengelola data materi, data tugas, data mata pelajaran, dan data nilai. Peserta dapat mengakses data peserta, data pengajar, data mata pelajaran, data materi, dan data tugas. Free user dapat mengakses info pengajar, info galeri, dan data pendaftaran.

Setelah perancangan selesai dilakukan, sistem informasi Rawa BaTIK dibangun menggunakan 
bahasa pemrograman PHP. Hasil implementasi sistem informasi Rawa BaTIK dapat dilihat pada Gambar 5 sampai dengan Gambar 12.

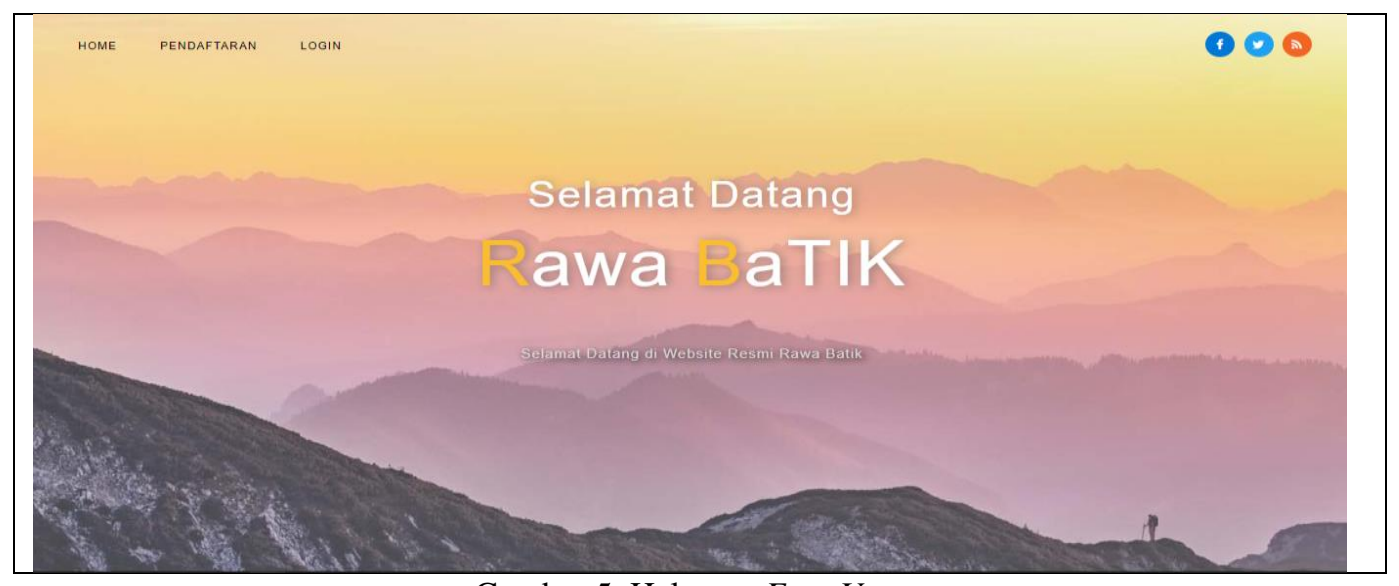

Gambar 5. Halaman Free User

Gambar 5 merupakan implementasi halaman free user. Halaman ini meliputi menu home, pendaftaran, dan login. Menu home memberikan informasi mengenai Rawa BaTIK. Jika menu pendaftaran diklik, maka akan menuju halaman pendaftaran yang disajikan pada Gambar 6. Jika menu login diklik, maka akan menuju halaman login yang disajikan pada Gambar 7.

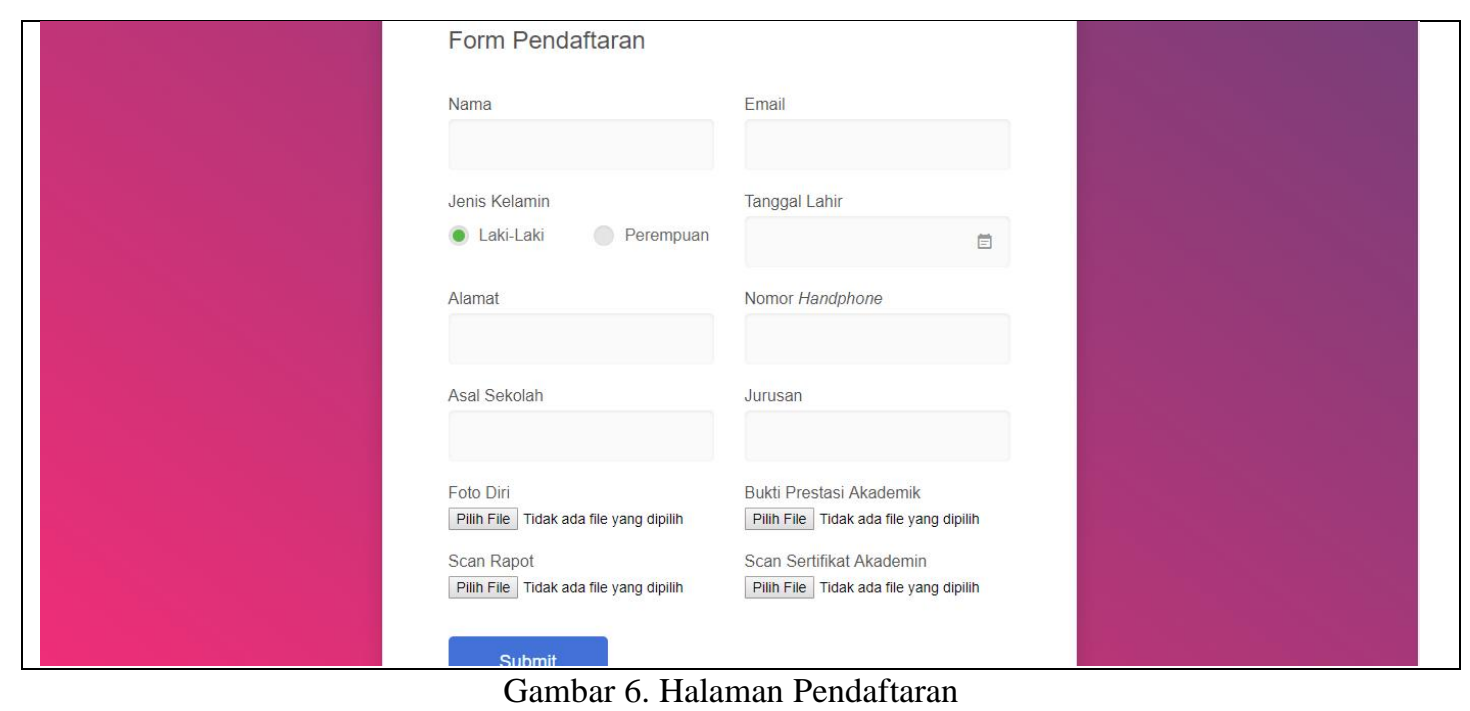

Gambar 6 merupakan halaman pendaftaran yang harus diisi oleh calon peserta meliputi nama, jenis kelamin, alamat, sekolah, jurusan email, tanggal lahir, nomor handphone, foto diri, rapot, bukti prestasi akademik, dan scan sertifikat akademik. Jika calon peserta telah yakin dengan isian pada halaman pendaftaran, maka calon peserta harus mengklik tombol submit. 


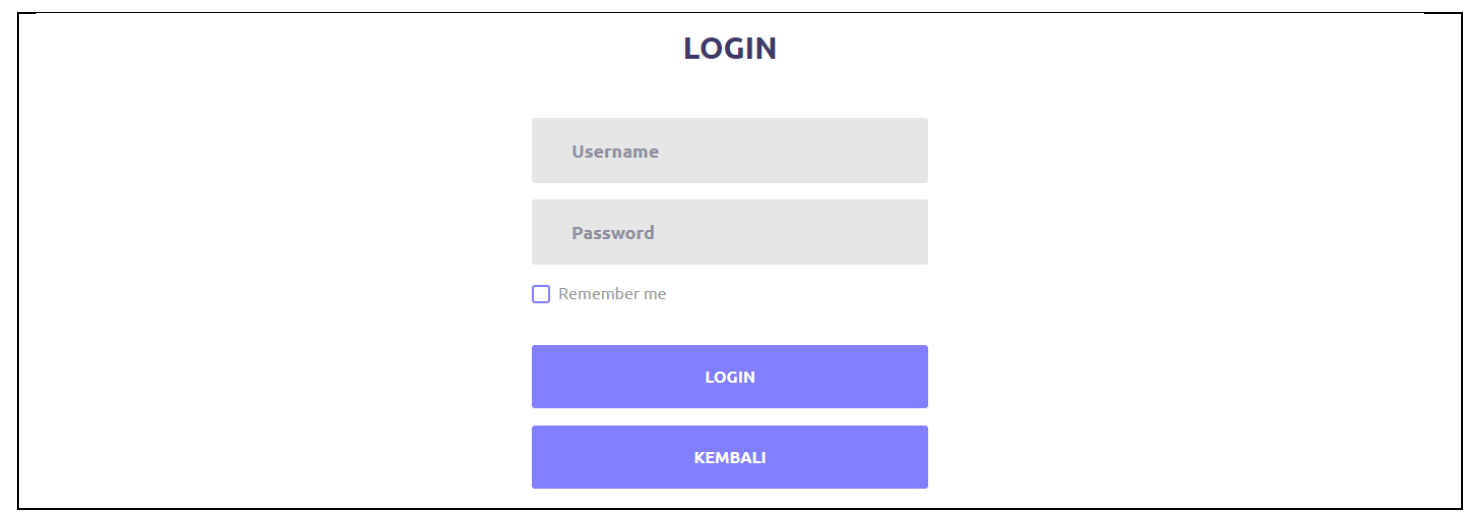

Gambar 7. Halaman Login

Gambar 7 merupakan halaman login Sistem Informasi Rawa BaTIK dimana terdapat dua text box untuk memasukkan username dan password, kemudian ada dua buah tombol untuk login dan batal, jika login maka akan masuk ke sistem dan diperiksa apakah peserta, instruktur, petugas atau admin dan jika batal maka akan kembali ke halaman freeuser (Gambar 5).

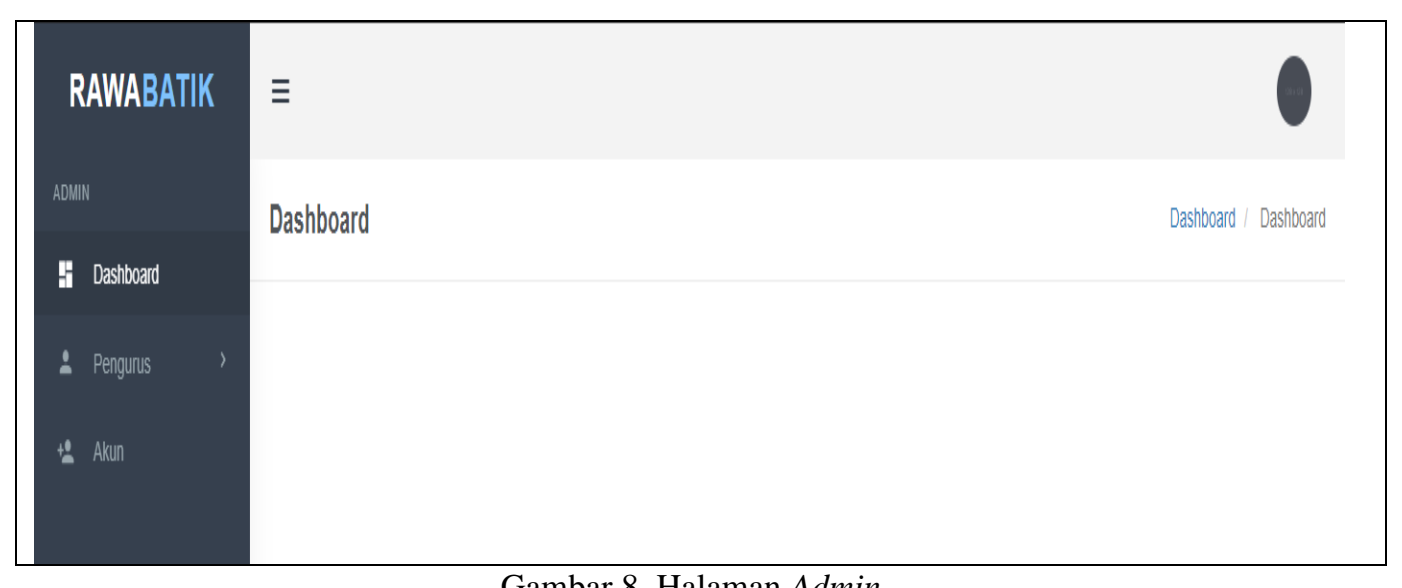

Gambar 8. Halaman Admin

Gambar 8 merupakan halaman Admin Sistem Informasi Rawa BaTIK yang memiliki beberapa menu disamping kiri diantaranya yaitu, Dashboard, dropdown untuk pengurus dan menu akun.

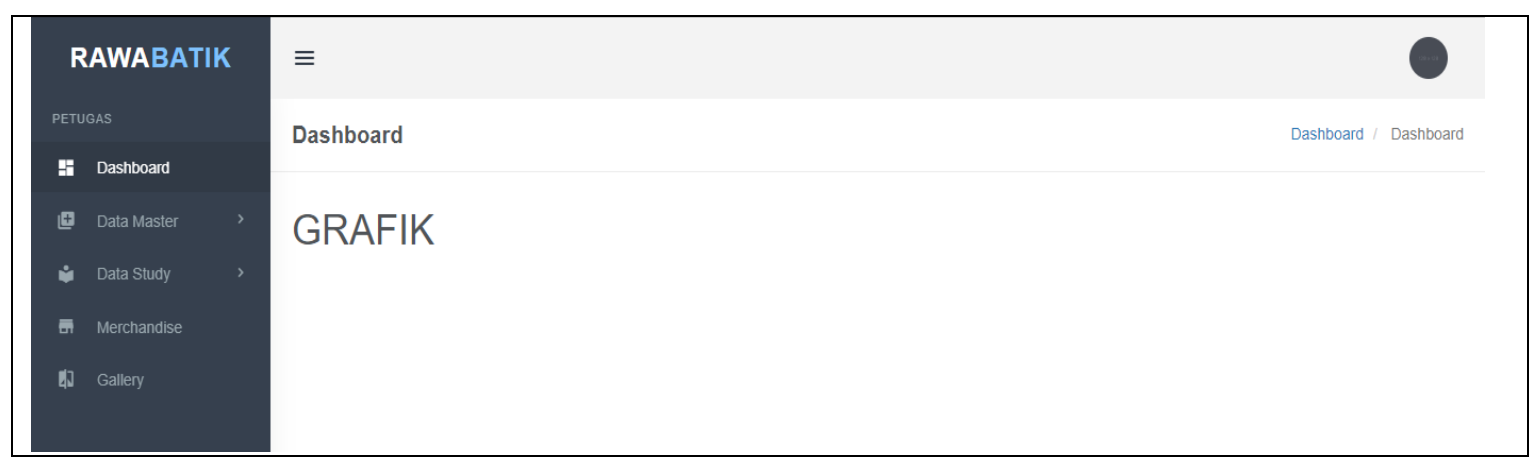

Gambar 9. Halaman Petugas

Gambar 9 merupakan halaman petugas Sistem Informasi Rawa BaTIK yang memiliki beberapa menu disamping kiri diantaranya yaitu, Dashboard, Data Master, Data Study, Merchandise dan Gallery. 

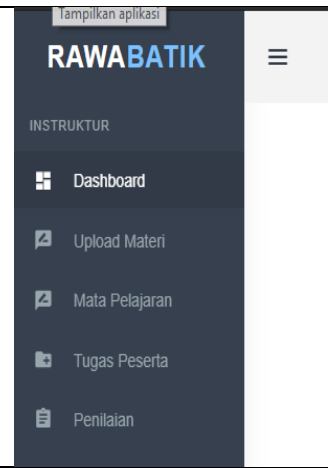

Gambar 10. Halaman Instruktur

Gambar 10 merupakan halaman instruktur Sistem Informasi Rawa BaTIK yang memiliki beberapa menu disamping kiri diantaranya yaitu, Dashboard, Upload Materi, Mata Pelajaran, Tugas Peserta dan Penilaian.

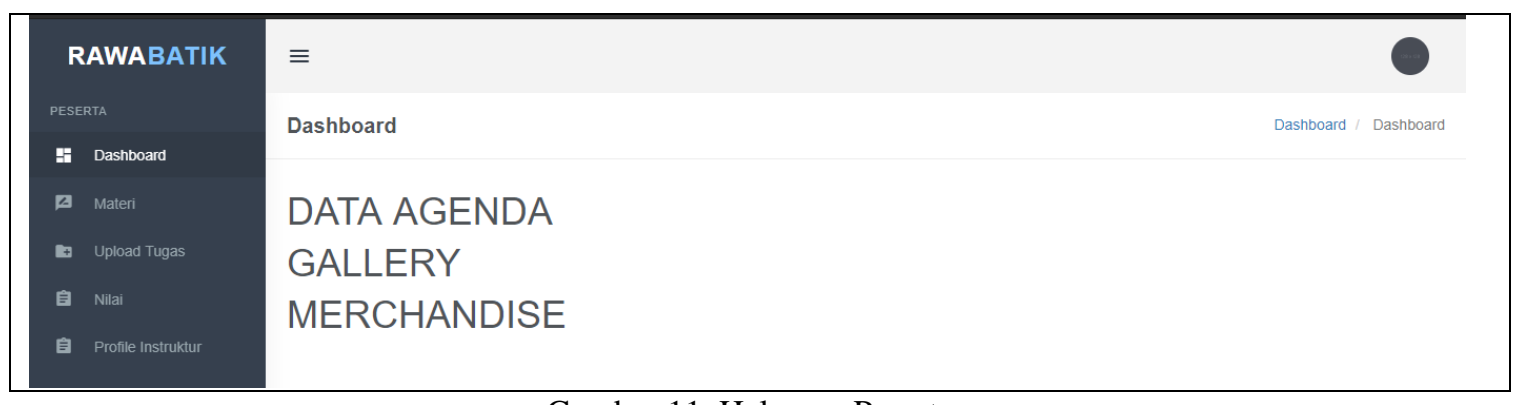

Gambar 11. Halaman Peserta

Gambar 11 merupakan halaman peserta Sistem Informasi Rawa BaTIK yang memiliki beberapa menu disamping kiri diantaranya yaitu, Dashboard, Materi, Upload Tugas, Nilai, dan Profile Instruktur.

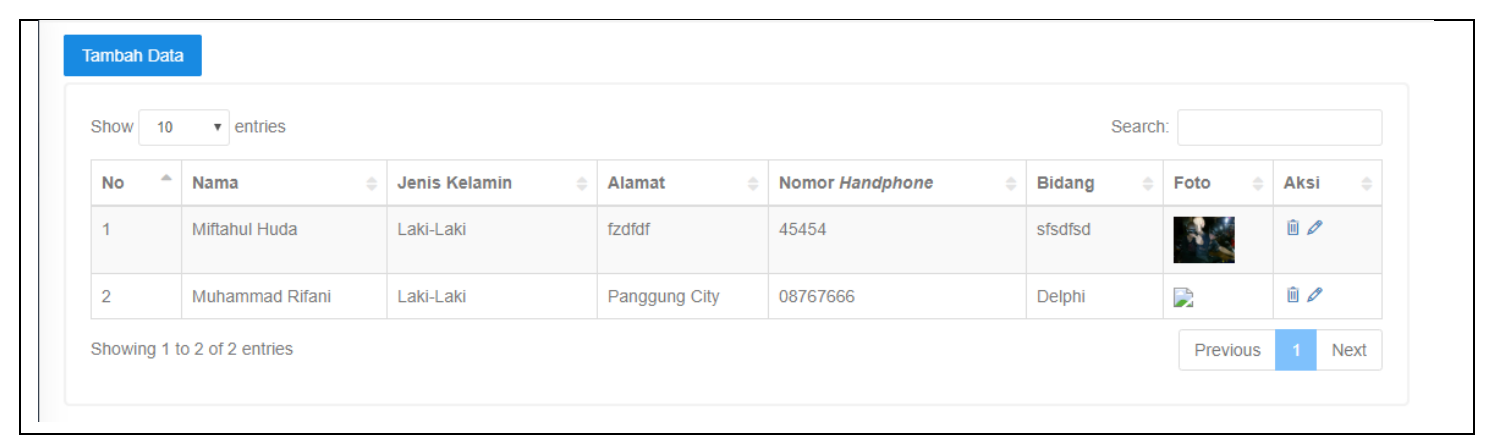

Gambar 12. Halaman Tampil Data

Gambar 12 merupakan halaman tampil data Sistem Informasi Rawa BaTIK yang memiliki beberapa menu yaitu menu tambah data, hapus edit, dan cari data.

Hasil pengujian sistem menggunakan black box disajikan pada Tabel 1.

Tabel 1. Hasil Pengujian Sistem

\begin{tabular}{|c|l|l|l|c|}
\hline No & Skenario Pengujian & \multicolumn{1}{|c|}{ Test Case } & \multicolumn{1}{|c|}{ Hasil Dicapai } & Kesimpulan \\
\hline 1 & Mengisi form login & $\begin{array}{l}\text { Username: } \\
\text { Password: }\end{array}$ & $\begin{array}{l}\text { User dapat masuk ke } \\
\text { halaman dashboard atau } \\
\text { halaman sesuai Levelnya }\end{array}$ & Berhasil \\
\hline 2 & Tidak mengisi form & Username: & Login gagal, username dan & Berhasil \\
\hline
\end{tabular}




\begin{tabular}{|c|c|c|c|c|}
\hline No & Skenario Pengujian & Test Case & Hasil Dicapai & Kesimpulan \\
\hline & $\operatorname{login}$ & Password: & $\begin{array}{l}\text { password salah dan kembali } \\
\text { ke halaman login }\end{array}$ & \\
\hline 3 & User Logout & Klik menu logout & $\begin{array}{l}\text { Logout berhasil, kembali ke } \\
\text { halaman login }\end{array}$ & Berhasil \\
\hline 4 & $\begin{array}{l}\text { Pendaftaran peserta } \\
\text { baru oleh free user }\end{array}$ & $\begin{array}{l}\text { Isikan data lengkap kemudian } \\
\text { klik }\end{array}$ & $\begin{array}{l}\text { Data pendaftar berhasil } \\
\text { disimpan verifikasi email } \\
\text { berhasil dikirim }\end{array}$ & Berhasil \\
\hline 5 & Input data akun & $\begin{array}{l}\text { Isikan data akun kemudian } \\
\text { klik simpan }\end{array}$ & Data akun berhasil disimpan & Berhasil \\
\hline 6 & Lihat data akun & Klik menu lihat data akun & $\begin{array}{l}\text { Menampilkan list data akun } \\
\text { yang sudah tersimpan }\end{array}$ & Berhasil \\
\hline 7 & Hapus data akun & $\begin{array}{l}\text { Klik menu hapus pada kolom } \\
\text { aksi tabel akun }\end{array}$ & Data akun berhasil dihapus & Berhasil \\
\hline 8 & Edit data akun & $\begin{array}{l}\text { Klik menu edit pada kolom } \\
\text { aksi tabel akun kemudian } \\
\text { Isikan data akun pada form } \\
\text { akun, kemudian klik simpan }\end{array}$ & Data akun berhasil dirubah & Berhasil \\
\hline 9 & Lihat data pendaftar & Klik menu detail pendaftar & $\begin{array}{l}\text { Menampilkan detail data } \\
\text { satu pendaftar yang sudah } \\
\text { tersimpan. }\end{array}$ & Berhasil \\
\hline 10 & Input data peserta & $\begin{array}{l}\text { Isikan data peserta kemudian } \\
\text { klik simpan }\end{array}$ & $\begin{array}{l}\text { Data peserta berhasil } \\
\text { disimpan }\end{array}$ & Berhasil \\
\hline 11 & Lihat data peserta & Klik menu lihat data peserta & $\begin{array}{l}\text { Menampilkan data peserta } \\
\text { yang sudah tersimpan }\end{array}$ & Berhasil \\
\hline 12 & Edit data peserta & $\begin{array}{l}\text { Klik menu edit pada kolom } \\
\text { aksi tabel peserta kemudian } \\
\text { Isikan data peserta pada form } \\
\text { peserta, kemudian klik simpan }\end{array}$ & $\begin{array}{l}\text { Data peserta berhasil } \\
\text { dirubah }\end{array}$ & Berhasil \\
\hline 13 & Hapus data peserta & $\begin{array}{l}\text { Klik menu hapus pada kolom } \\
\text { aksi tabel akun }\end{array}$ & $\begin{array}{l}\text { Data peserta berhasil } \\
\text { dihapus }\end{array}$ & Berhasil \\
\hline 14 & Input data instruktur & $\begin{array}{l}\text { Isikan data instruktur } \\
\text { kemudian klik simpan }\end{array}$ & $\begin{array}{l}\text { Data instruktur berhasil } \\
\text { disimpan }\end{array}$ & Berhasil \\
\hline 15 & Lihat data instruktur & Klik menu lihat data instruktur & $\begin{array}{l}\text { Menampilkan data instruktur } \\
\text { yang sudah tersimpan }\end{array}$ & Berhasil \\
\hline 16 & Edit data peserta & $\begin{array}{l}\text { Klik menu edit pada kolom } \\
\text { aksi tabel instruktur kemudian } \\
\text { Isikan data instruktur pada } \\
\text { form instruktur, kemudian klik } \\
\text { simpan }\end{array}$ & $\begin{array}{l}\text { Data peserta berhasil } \\
\text { dirubah }\end{array}$ & Berhasil \\
\hline 17 & Hapus data instruktur & $\begin{array}{l}\text { Klik menu hapus pada kolom } \\
\text { aksi tabel akun }\end{array}$ & $\begin{array}{l}\text { Data instruktur berhasil } \\
\text { dihapus }\end{array}$ & Berhasil \\
\hline 18 & Input data petugas & $\begin{array}{l}\text { Isikan data petugas kemudian } \\
\text { klik simpan }\end{array}$ & $\begin{array}{l}\text { Data petugas berhasil } \\
\text { disimpan }\end{array}$ & Berhasil \\
\hline 19 & Lihat data petugas & Klik menu lihat data petugas & $\begin{array}{l}\text { Menampilkan data petugas } \\
\text { yang sudah tersimpan }\end{array}$ & Berhasil \\
\hline 20 & Edit data petugas & $\begin{array}{l}\text { Klik menu edit pada kolom } \\
\text { aksi tabel petugas kemudian } \\
\text { Isikan data petugas pada form } \\
\text { petugas, kemudian klik } \\
\text { simpan }\end{array}$ & $\begin{array}{l}\text { Data peserta berhasil } \\
\text { dirubah }\end{array}$ & Berhasil \\
\hline 21 & Hapus data petugas & $\begin{array}{l}\text { Klik menu hapus pada kolom } \\
\text { aksi tabel petugas }\end{array}$ & $\begin{array}{l}\text { Data petugas berhasil } \\
\text { dihapus }\end{array}$ & Berhasil \\
\hline 22 & Input data agenda & $\begin{array}{l}\text { Isikan data agenda kemudian } \\
\text { klik simpan }\end{array}$ & $\begin{array}{l}\text { Data agenda berhasil } \\
\text { disimpan }\end{array}$ & Berhasil \\
\hline 23 & Lihat data agenda & Klik menu lihat data agenda & $\begin{array}{l}\text { Menampilkan data petugas } \\
\text { yang sudah tersimpan }\end{array}$ & Berhasil \\
\hline 24 & Edit data Agenda & pada kolom aksi tabel agenda & Data peserta berhasil & Berhasil \\
\hline
\end{tabular}




\begin{tabular}{|c|c|c|c|c|}
\hline No & Skenario Pengujian & Test Case & Hasil Dicapai & Kesimpulan \\
\hline & & $\begin{array}{l}\text { kemudian Isikan data agenda } \\
\text { pada form agenda, kemudian } \\
\text { klik simpan }\end{array}$ & dirubah & \\
\hline 25 & Hapus data agenda & $\begin{array}{l}\text { Klik menu hapus pada kolom } \\
\text { aksi tabel petugas }\end{array}$ & $\begin{array}{l}\text { Data agenda berhasil } \\
\text { dihapus }\end{array}$ & Berhasil \\
\hline 26 & $\begin{array}{l}\text { Input data mata } \\
\text { pelajaran }\end{array}$ & $\begin{array}{l}\text { Isikan data mata pelajaran } \\
\text { kemudian klik simpan }\end{array}$ & $\begin{array}{l}\text { Data matapelajaran berhasil } \\
\text { disimpan }\end{array}$ & Berhasil \\
\hline 27 & $\begin{array}{l}\text { Lihat data mata } \\
\text { pelajaran }\end{array}$ & $\begin{array}{l}\text { Klik menu lihat data mata } \\
\text { pelajaran }\end{array}$ & $\begin{array}{l}\text { Menampilkan data mata } \\
\text { pelajaran yang sudah } \\
\text { tersimpan }\end{array}$ & Berhasil \\
\hline 28 & $\begin{array}{l}\text { Edit data mata } \\
\text { pelajaran }\end{array}$ & $\begin{array}{l}\text { pada kolom aksi tabel mata } \\
\text { pelajaran kemudian Isikan } \\
\text { data mata pelajaran pada form } \\
\text { mata pelajaran, kemudian klik } \\
\text { simpan }\end{array}$ & $\begin{array}{l}\text { Data mata pelajaran berhasil } \\
\text { dirubah }\end{array}$ & Berhasil \\
\hline 29 & Hapus mata pelajaran & $\begin{array}{l}\text { Klik menu hapus pada kolom } \\
\text { aksi tabel mata pelajaran }\end{array}$ & $\begin{array}{l}\text { Data mata pelajaran berhasil } \\
\text { dihapus }\end{array}$ & Berhasil \\
\hline 30 & Input data galleri & $\begin{array}{l}\text { Isikan data galleri kemudian } \\
\text { klik simpan }\end{array}$ & $\begin{array}{l}\text { Data galleri berhasil } \\
\text { disimpan }\end{array}$ & Berhasil \\
\hline 31 & Lihat data galleri & Klik menu lihat data galleri & $\begin{array}{l}\text { Menampilkan data galleri } \\
\text { yang sudah tersimpan }\end{array}$ & Berhasil \\
\hline 32 & Edit data galleri & $\begin{array}{l}\text { pada kolom aksi tabel galleri } \\
\text { kemudian Isikan data galleri } \\
\text { pada form galleri, kemudian } \\
\text { klik simpan }\end{array}$ & Data galleri berhasil dirubah & Berhasil \\
\hline 33 & Hapus data galleri & $\begin{array}{l}\text { Klik menu hapus pada kolom } \\
\text { aksi tabel galleri }\end{array}$ & $\begin{array}{l}\text { Data mata pelajaran berhasil } \\
\text { dihapus }\end{array}$ & Berhasil \\
\hline 34 & Input merchandise & $\begin{array}{l}\text { Isikan data merchandise } \\
\text { kemudian klik simpan }\end{array}$ & $\begin{array}{l}\text { Data merchandise berhasil } \\
\text { disimpan }\end{array}$ & Berhasil \\
\hline 35 & Lihat merchandise & $\begin{array}{l}\text { Klik menu lihat data } \\
\text { merchandise }\end{array}$ & $\begin{array}{l}\text { Menampilkan data } \\
\text { merchandise yang sudah } \\
\text { tersimpan }\end{array}$ & Berhasil \\
\hline 36 & $\begin{array}{l}\text { Edit data } \\
\text { merchandise }\end{array}$ & $\begin{array}{l}\text { pada kolom aksi tabel } \\
\text { merchandise kemudian Isikan } \\
\text { data merchandise pada form } \\
\text { merchandise, kemudian klik } \\
\text { simpan }\end{array}$ & Data galleri berhasil dirubah & Berhasil \\
\hline 37 & $\begin{array}{l}\text { Hapus data } \\
\text { merchandise }\end{array}$ & $\begin{array}{l}\text { Klik menu hapus pada kolom } \\
\text { aksi tabel galleri }\end{array}$ & $\begin{array}{l}\text { Data merchandise berhasil } \\
\text { dihapus }\end{array}$ & Berhasil \\
\hline 38 & Input data nilai & $\begin{array}{l}\text { Isikan data nilai kemudian } \\
\text { klik simpan }\end{array}$ & Data nilai berhasil disimpan & Berhasil \\
\hline 39 & Lihat data nilai & Klik menu lihat data nilai & $\begin{array}{l}\text { Data merchandise berhasil } \\
\text { disimpan }\end{array}$ & Berhasil \\
\hline 40 & Edit data nilai & $\begin{array}{l}\text { Klik menu lihat data nilai } \\
\text { pada kolom aksi tabel nilai } \\
\text { kemudian Isikan data nilai } \\
\text { pada form nilai, kemudian klik } \\
\text { simpan }\end{array}$ & Data galleri berhasil dirubah & Berhasil \\
\hline 41 & Hapus data nilai & $\begin{array}{l}\text { Klik menu hapus pada kolom } \\
\text { aksi tabel nilai }\end{array}$ & Data nilai berhasil dihapus & Berhasil \\
\hline 42 & Input data materi & $\begin{array}{l}\text { Isikan data materi kemudian } \\
\text { klik simpan }\end{array}$ & Data nilai materi disimpan & Berhasil \\
\hline 43 & Lihat data materi & Klik menu lihat data materi & $\begin{array}{l}\text { Data materi berhasil } \\
\text { disimpan }\end{array}$ & Berhasil \\
\hline 44 & Edit data materi & $\begin{array}{l}\text { Klik menu lihat data materi } \\
\text { pada kolom aksi tabel nilai } \\
\text { kemudian Isikan data materi }\end{array}$ & Data materi berhasil dirubah & Berhasil \\
\hline
\end{tabular}




\begin{tabular}{|c|c|c|c|c|}
\hline No & Skenario Pengujian & Test Case & Hasil Dicapai & Kesimpulan \\
\hline & & $\begin{array}{l}\text { pada form materi, kemudian } \\
\text { klik simpan }\end{array}$ & & \\
\hline 45 & Hapus data materi & $\begin{array}{l}\text { Klik menu hapus pada kolom } \\
\text { aksi tabel materi }\end{array}$ & Data materi berhasil dihapus & Berhasil \\
\hline 46 & Download materi & $\begin{array}{l}\text { Klik download pada halaman } \\
\text { materi }\end{array}$ & $\begin{array}{l}\text { Data materi berhasil di } \\
\text { download }\end{array}$ & Berhasil \\
\hline 47 & Input tugas & $\begin{array}{l}\text { Isikan data tugas kemudian } \\
\text { klik simpan }\end{array}$ & Data tugas berhasil disimpan & Berhasil \\
\hline 48 & Download tugas & $\begin{array}{l}\text { Klik download pada halaman } \\
\text { tugas }\end{array}$ & $\begin{array}{l}\text { Data tugas berhasil di } \\
\text { download }\end{array}$ & Berhasil \\
\hline
\end{tabular}

Berdasarkan hasil pengujian sistem oleh Sekretaris Dinas Komunikasi dan Informatika Kabupaten Tanah Bumbu yang disajikan pada Tabel 1 terlihat bahwa semua fitur telah berhasil diujicobakan, sehingga sistem informasi Rawa BaTIK dapat digunakan untuk mendukung pengelolaan administrasi Rawa BaTIK. Adanya fitur untuk pendaftaran, materi, tugas, dan nilai dapat membantu pengarsipan pelaksanaan kegiatan Rawa BaTIK lebih rapi, sehingga mudah untuk dilihat kembali.

\section{KESIMPULAN}

Sistem Informasi Rawa BaTIK telah berhasil dirancang dan dibangun menggunakan bahasa pemrograman PHP sehingga dapat mempermudah calon peserta yang melakukan pendaftaran tanpa harus datang langsung ke Dinas Komunikasi dan Informatika. Guna pengembangan sistem informasi ini, untuk ke depannya dapat ditambahkan fitur deadline waktu untuk setiap tugas yang diberikan kepada peserta dan fitur yang membantu instruktur agar bisa langsung menilai tugas yang dikumpulkan peserta dalam sistem.

\section{DAFTAR PUSTAKA}

Lestari, E. W. \& Mirchandini, N. Y. (2018). Sistem Informasi Pendaftaran Anggota Baru pada Palang Merah Indonesia (PMI) Jakarta. Paradigma Jurnal Komputer dan Informatika Universitas Bina Sarana Informatika Volume XXI No 2 September 2018. pp 173-178.

Rosa \& Shalahuddin, M. (2013). Rekayasa Perangkat Lunak. Bandung: Informatika

Sarwindah. (2018). Sistem Pendaftaran Siswa Baru pada SMP N 1 Kelapa Berbasis Web. Jurnal SISFOKOM Volume 7 Nomor 2 September 2018. Pp 110-115.

Sidik, F. \& Rahmawati, M. (2018). Perancangan Sistem Informasi Pendaftaran Siswa Baru Berbasis Web pada SMK Bina Putra Jakarta. Paradigma Volume XX Nomor 1 Maret 2018. pp 119-128. 